\title{
Expression profiling of macrophages from subjects with atherosclerosis to identify novel susceptibility genes
}

\author{
DANIEL A. HÄGG ${ }^{1}$, MARGARETA JERNÅS ${ }^{1}$, OLLE WIKLUND ${ }^{1}$, DAG S. THELLE ${ }^{2}$, \\ BJÖRN FAGERBERG ${ }^{1}$, PER ERIKSSON ${ }^{3}$, ANDERS HAMSTEN ${ }^{3}$, BOB OLSSON ${ }^{1}$, \\ BJÖRN CARLSSON $^{1}$, LENA M.S. CARLSSON ${ }^{1}$ and PER-ARNE SVENSSON ${ }^{1}$ \\ ${ }^{1}$ Department of Molecular and Clinical Medicine, Sahlgrenska Academy, University of Göteborg, Göteborg, Sweden; \\ ${ }^{2}$ Department of Biostatistics, Institute of Basic Medical Sciences, University of Oslo, Oslo, Norway; \\ ${ }^{3}$ Department of Medicine, Atherosclerosis Research Unit, Karolinska University Hospital, Stockholm, Sweden
}

Received February 1, 2008; Accepted March 11, 2008

\begin{abstract}
Although a number of environmental risk factors for atherosclerosis have been identified, heredity seems to be a significant independent risk factor. The aim of our study was to identify novel susceptibility genes for atherosclerosis. The screening process consisted of three steps. First, expression profiles of macrophages from subjects with atherosclerosis were compared to macrophages from control subjects. Secondly, the subjects were genotyped for promoter region polymorphisms in genes with altered gene expression. Thirdly, a population of subjects with coronary heart disease and control subjects were genotyped to test for an association with identified polymorphisms that affected gene expression. Twenty-seven genes were differentially expressed in both macrophages and foam cells from subjects with atherosclerosis. Three of these genes, IRS2, CD86 and SLC11A1 were selected for further analysis. Foam cells from subjects homozygous for the $\mathrm{C}$ allele at the $-765 \mathrm{C} \rightarrow \mathrm{T}$ SNP located in the promoter region of IRS2 had increased gene expression compared to foam cells from subjects with the nonCC genotype. Also, macrophages and foam cells from subjects homozygous for allele 2 at a repeat element in the promoter region of SLC11A1 had increased gene expression compared to macrophages and foam cells from subjects with the non22 genotype. Genotyping of 512 pairs of subjects with coronary heart disease (CHD) and matched controls revealed that subjects homozygous for $\mathrm{C}$ of the IRS2 SNP had an increased risk for $\mathrm{CHD}$; odds ratio $1.43, \mathrm{p}=0.010$. Immunohistochemical staining of human carotid plaques showed that IRS2 expression was localised to macrophages and
\end{abstract}

Correspondence to: Daniel Hägg, Vita Stråket 15, S-413 45 Göteborg, Sweden

E-mail: daniel.hagg@medic.gu.se

Key words: atherosclerosis, macrophages, genomics, genotyping, foam cells, IRS2 endothelial cells in vivo. Our method provides a reliable approach for identifying susceptibility genes for atherosclerosis, and we conclude that elevated IRS2 gene expression in macrophages may be associated with an increased risk of CHD.

\section{Introduction}

Family history seems to be the most important independent risk factor for the development of atherosclerosis (1). Although several Mendelian disorders, such as familial hypercholesterolemia, are known to cause atherosclerosis, they have a low prevalence and only account for a small fraction of the reported incidences (2). It is plausible to assume that multiple genes contribute to the development of atherosclerosis by affecting an individual's response to risk factors. Furthermore, risk factors such as high blood pressure and high cholesterol levels in themselves have a complex genetic influence (1). It is therefore difficult to predict disease progress and to choose an optimal therapeutic strategy in individual patients (3).

Identification of susceptibility genes for atherosclerosis, each with only a limited individual contribution to the disease development, poses a great challenge. It has been proposed that much of the genetic susceptibility to complex diseases is a result of single nucleotide polymorphisms (SNPs) that influence gene expression, and it is estimated that $\sim 6 \%$ of all human genes have functional regulatory variants (4). Thus, analysis of variations in gene expression could potentially identify susceptibility genes for complex diseases, which opens the possibility for global expression analysis to identify such genes.

The aim of the study was to search for susceptibility genes for atherosclerosis. We designed a multi-step procedure based on a clinical and population-based sample of subjects with acute coronary syndrome, their first-degree relatives, and a matched control group from the general population called the INTERGENE population study. In the first step, expression profiles of macrophages from subjects with atherosclerosis were compared to macrophages from control subjects to identify genes with an altered gene expression. In the second 
step, the association between altered gene expression and the genotype of promoter region polymorphisms was tested. In the third step, the association between the genotype of these polymorphisms and coronary heart disease (CHD) was examined.

We found that insulin receptor substrate 2 (IRS2) was expressed at higher levels in macrophages from subjects with atherosclerosis than in macrophages from control subjects. A SNP in the promoter region of IRS2 was associated with higher gene expression in macrophages, and subjects homozygous for the C allele of this SNP had an increased risk of CHD. Our results indicate that IRS2 might be a susceptibility gene for atherosclerosis and CHD.

\section{Materials and methods}

Study outline. Subjects with atherosclerosis and heredity for $\mathrm{CHD}$ and control subjects with no atherosclerosis and no family history of CHD were identified from the INTERGENE population study (details below). Using DNA microarray analysis, expression profiles of macrophages and foam cells were generated from these subjects and compared to identify genes with an altered gene expression. The study subjects were genotyped for known polymorphisms in the promoter regions of genes identified by gene expression analysis. Polymorphisms affecting gene expression in macrophages from subjects with atherosclerosis compared to control subjects were then genotyped in a case-control cohort of the INTERGENE study $(n=1226)$. This procedure is outlined in Fig. 1.

Subjects. The INTERGENE study was designed to investigate the interplay between genetic, environmental and life style risk factors on the total risk of CHD (http://www2.sahlgrenska. gu.se/intergene/eng/index.jsp). At the time of this study, it was comprised of 670 patients with acute coronary syndromes (myocardial infarction or unstable angina pectoris), 400 firstdegree relatives of the patients (siblings, children or parents), and 3600 randomly selected healthy controls from western Sweden (5). An age- and sex-matched case control subpopulation from the INTERGENE study consisting of 613 patients with CHD and 613 non-related controls from the INTERGENE study was used for genotyping studies. The participants gave informed consent, and the ethics committee of Göteborg University approved this study.

The Macrophage INTERGENE study is a subset of the INTERGENE study and was designed to search for potential atherosclerosis susceptibility genes (6). It consists of 15 subjects with atherosclerosis (inclusion criteria: first-degree relatives of the patient group and at least one atherosclerotic plaque in the carotid or femoral artery as assessed by ultrasound) and 15 age- and sex-matched healthy controls without family history of atherosclerotic disease (6). The clinical characteristics of these subjects were described previously (7).

Carotid atherosclerotic plaques were obtained as endarterectomy specimens from four caucasian patients operated on for symptomatic carotid artery stenosis at Sahlgrenska University Hospital within the framework of the Göteborg Atheroma Study Group (http://www.wlab.gu.se/GASG).

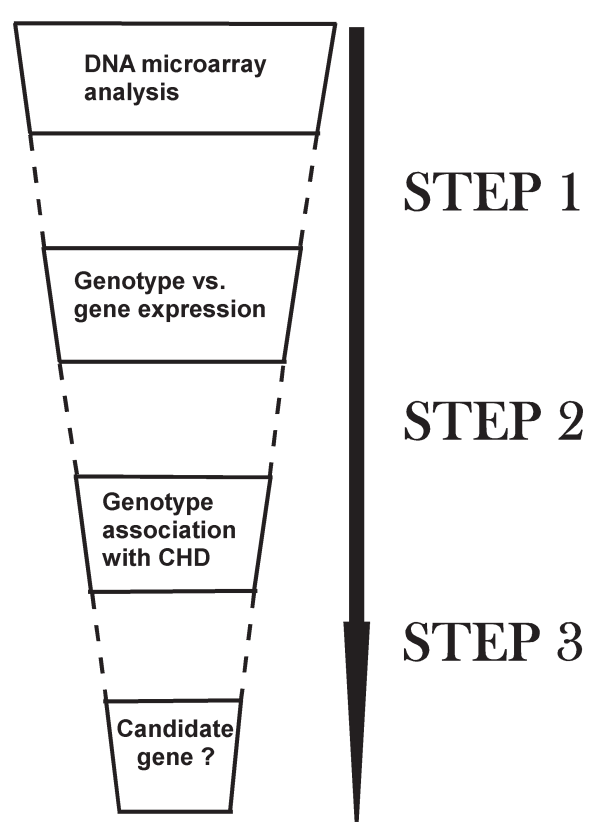

Figure 1. Schematic overview of the multi-step screening for novel susceptibility genes for atherosclerosis and CHD. Gene expression profiles of macrophages from subjects with atherosclerosis and macrophages from control subjects were compared in order to identify genes with an altered gene expression, step 1. Known promoter region polymorphisms of identified genes were genotyped in the study subjects to test for the association between genotype and macrophage gene expression, step 2 . Polymorphisms that affected gene expression were genotyped in a casecontrol cohort of the INTERGENE study, subjects with CHD and paired control subjects, to identify potential susceptibility genes for atherosclerosis and coronary heart disease, step 3 .

Macrophage preparation. Monocytes from the participants of the Macrophage INTERGENE study were differentiated as described previously (8). Briefly, white blood cells were isolated from buffy coats, seeded and allowed to adhere for $1 \mathrm{~h}$. Non-adherent cells were removed by three washes with PBS, and adherent cells were then allowed to differentiate in Macrophage-SFM (Gibco BRL, Grand Island, NY) for 6 days.

LDL preparation and oxidation were performed as described previously (8). Briefly, human LDL (d 1.019-1.063 g/ $\mathrm{ml}$ ) was prepared by sequential ultra-centrifugation at $4^{\circ} \mathrm{C}$ of plasma from healthy, fasted male volunteers. The LDL was oxidized by storage at $4^{\circ} \mathrm{C}$ for 3 months to generate minimally modified LDL (mmLDL). The thiobarbituric acid reactive substance (TBARS) levels of the mmLDL were $5 \mathrm{nmol}$ malondialdehyde equivalents/mg protein. On day 7 , the macrophages were cultured with mmLDL (50 $\mu \mathrm{g}$ protein $/ \mathrm{ml})$ for $24 \mathrm{~h}$ to generate lipid-loaded macrophages, as a model for foam cells. The presence of foam cells is considered a hallmark of atherogenesis (8). The macrophages and foam cells were washed in PBS, and RNA was isolated using the RNeasy Kit (Qiagen, Hilden, Germany).

DNA microarray. Biotin-labeled target cRNA was hybridized to individual HG-U133A DNA microarrays and processed according to the manufacturer's protocol (Affymetrix, Santa Clara, CA). DNA microarrays were scanned using the G2500A GeneArray scanner (Hewlett Packard, Palo Alto, 
CA), and the output files were analyzed with Microarray suite 5 (Affymetrix). DNA microarrays were globally scaled to an average intensity of 100 . On average, $37 \%$ of the probe sets were classified as present. In all, four groups with 15 expression profiles in each group were generated, and macrophages and foam cells from subjects with atherosclerosis were compared to macrophages and foam cells from control subjects, respectively. Only genes with an average intensity signal $>50$ in at least one group (atherosclerosis or control subjects, macrophages or foam cells) were included. Genes that were upregulated in one group and downregulated in the other group were excluded.

The microarray data set can be viewed in its entirety at the GEO Accession viewer at the NIH homepage (http:// www.ncbi.nlm.nih.gov) series GSE9874.

Real-time RT-PCR. This procedure was performed as described (9). Briefly, reagents (TaqMan ${ }^{\circledR}$ Reverse Transcriptase reagents and TaqMan ${ }^{\circledR}$ Universal PCR Master mix) were purchased from Applied Biosystems (Foster City, CA). Assay-on-demand probes and primers for IRS2 (Hs00275843_a1) and pre-developed assay reagents for endogenous control human PPIA, 4333763T, were obtained from Applied Biosystems.

Genotyping. DNA was isolated from blood samples from the case control subpopulation in the INTERGENE study. For the genotyping of the $-765 \mathrm{C} \rightarrow \mathrm{T}$ SNP in the promoter region of IRS2, a restriction fragment length polymorphism assay was used. PCR was performed using 20-30 ng genomic DNA as starting material and primers forward 5'-CCTGGGTGG CATCTCCTC-3' and reverse 5'-GCTGCTGGTGTTGCT GCT-3'. The PCR products were incubated overnight with restriction enzyme BtgI. A cytosine nucleotide at -765 results in the restriction site CCGCGG, whereas a thymine nucleotide gives TCGCGG, which is not recognized by BtgI.

Fragment analysis was used for genotyping of the repeat element of SLC11A1. A PCR product was generated from 20-30 ng genomic DNA using primers forward 5'-GTCTTG GAACTCCAGATCAAAG-3' and reverse 5'-TTGCATATT CATGTCAATACCC-3'. PCR products were size-separated on an ABI PRISM 3100 genetic analyzer (Applied Biosystems) based on the number of GT-repeats in the promoter region.

TaqMan-based SNP analysis for genotyping of the rs2715267 SNP in the promoter region of CD86 was conducted using Assay-on-demand C_26193522_10 (Applied Biosystems) according to the manufacturer's protocol.

Immunohistochemistry. Carotid endarterectomy specimens isolated from 4 patients were divided into 3-mm sections, fixed in formalin for $24 \mathrm{~h}$ and embedded in paraffin. Sections $(4-\mu \mathrm{m})$ were taken from each block for immunohistochemistry. The sections were dewaxed, and antigens were unmasked with target retrieval solution (Dako Cytomation, Buckinghamshire, UK). Immunohistochemical staining was performed with a standard $\mathrm{LSAB}^{+}$System-HRP Kit (Dako) and with primary antibodies directed against macrophage marker CD68 (Novocastra Laboratories, Newcastle, UK) and IRS2 (Santa Cruz Biotechnology, Europe). Sections were incubated with primary antibody overnight. Staining was performed according to the manufacturer's instructions. As a negative control, the primary antibody was substituted with a universal negative control reagent (Dako).

Statistical analysis. All the genes present on the DNA microarrays were compared, and the Student's t-test was used to identify genes that were differentially expressed in macrophages and foam cells from subjects with atherosclerosis compared to the controls. $\mathrm{P}<0.05$ (two-tailed) was considered significant. The Kruskal Wallis test was used to test for association between genotype and gene expression.

For real-time RT-PCR, the unpaired Wilcoxon test was used to test for difference in gene expression between macrophages from subjects with atherosclerosis and control subjects, and the paired Wilcoxon test was used to test for differences in gene expression between macrophages and foam cells from the same individual. Results were expressed as the mean \pm SEM. The Mantel-Haenszel common odds ratio estimate and the McNemar's test were used to test for the association between CHD and the genotype in matched casecontrol pairs, analyzing the occurrence of discordant pairs.

\section{Results}

Expression profiling. Twenty-seven genes had a significantly altered gene expression in macrophages and foam cells from subjects with atherosclerosis compared to the controls (Table I). Gene expression of 7 of the 27 regulated genes was also significantly affected in foam cell formation in both the atherosclerosis and control group. Among the identified genes were both genes that were previously described in the context of atherosclerosis, insulin receptor substrate 2 (IRS2) $(11,12)$ and CD86 $(10)$, as well as several novel findings, such as SLC11A1 and KIAA1522. One of the genes with an altered gene expression, CD44, was studied in a previous article (6).

Three genes were selected for validation as potential susceptibility genes for atherosclerosis. IRS2 and CD86 were chosen since both genes were previously shown to affect the development of atherosclerosis in mice $(10,11)$. SLC11A1, also known as NRAMP1, was chosen since it is located in a chromosomal region previously linked to CHD (12).

Association between genotype and gene expression. A promoter region $\mathrm{SNP},-765 \mathrm{C} \rightarrow \mathrm{T}$, was previously shown to affect IRS2 gene expression (13). This SNP was genotyped in the Macrophage INTERGENE study. Foam cells from subjects homozygous for C, CC genotype, had higher IRS2 expression than foam cells from subjects with the CT and TT genotype $(\mathrm{P}=0.044)$ (Fig. 2A).

A promoter region repeat element of SLC11A1 was previously shown to affect gene expression (14). The participants of the Macrophage INTERGENE study were genotyped for the two most prevalent alleles of this repeat element, allele 2 and 3. Subjects homozygous for allele 2, 22 genotype, had higher gene expression in both macrophages $(\mathrm{P}=0.009)$ and foam cells $(\mathrm{P}=0.015)$ than subjects with the 23 and 33 genotype (Fig. 2B).

The SNP in the promoter region of CD86, $-3479 \mathrm{G} \rightarrow \mathrm{T}$ rs2715267, was shown to affect binding affinity for nuclear 
Table I. Genes that were differentially expressed in subjects with atherosclerosis compared to control subjects in macrophages and in foam cells. ${ }^{\mathrm{a}}$

\begin{tabular}{|c|c|c|c|c|c|c|}
\hline Gene symbol & $\begin{array}{l}\text { Macrophages } \\
\text { Ath vs control }\end{array}$ & $\begin{array}{l}\text { Foam cells } \\
\text { Ath vs control }\end{array}$ & $\begin{array}{l}\text { Control foam cells/ } \\
\text { macrophages }\end{array}$ & $\begin{array}{l}\text { Ath foam cells/ } \\
\text { macrophages }\end{array}$ & $\begin{array}{l}\text { Chromosomal } \\
\text { location }\end{array}$ & $\begin{array}{l}\text { Previous QTL } \\
\text { linkage studies }\end{array}$ \\
\hline $\mathrm{ABCC}^{\mathrm{c}}$ & $0.0232^{\mathrm{b}}$ & $0.0032^{\mathrm{b}}$ & $0.0456^{\mathrm{b}}$ & $0.0000^{\mathrm{b}}$ & $17 \mathrm{q} 22$ & \\
\hline ANP32A & $0.0108^{\mathrm{b}}$ & $0.0266^{\mathrm{b}}$ & 0.8535 & 0.2200 & $15 q 22.3-q 23$ & \\
\hline ARF6 & $0.0139^{\mathrm{b}}$ & $0.0301^{\mathrm{b}}$ & 0.1021 & 0.4399 & $7 q 22.1$ & \\
\hline CAMK2G ${ }^{\mathrm{c}}$ & $0.0471^{\mathrm{b}}$ & $0.0191^{\mathrm{b}}$ & $0.0035^{\mathrm{b}}$ & $0.0017^{\mathrm{b}}$ & $10 q 22$ & \\
\hline $\mathrm{CD} 44$ & $0.0135^{\mathrm{b}}$ & $0.0248^{\mathrm{b}}$ & 0.4127 & 0.5042 & $11 \mathrm{p} 13$ & FCHL (33) \\
\hline CD86 & $0.0212^{\mathrm{b}}$ & $0.0125^{\mathrm{b}}$ & 0.9905 & $0.0190^{\mathrm{b}}$ & $3 q 21$ & \\
\hline COPS7A & $0.0410^{\mathrm{b}}$ & $0.0060^{\mathrm{b}}$ & 0.4012 & 0.4743 & $12 \mathrm{p} 13.31$ & Homol (34) \\
\hline CRAT & $0.0220^{\mathrm{b}}$ & $0.0416^{\mathrm{b}}$ & 0.0627 & $0.0008^{\mathrm{b}}$ & $9 q 34.1$ & \\
\hline EPB41L1 & $0.0341^{\mathrm{b}}$ & $0.0034^{\mathrm{b}}$ & 0.0879 & 0.6667 & $20 q 11.2-q 12$ & MI (35) \\
\hline EPB41L1 & $0.0152^{\mathrm{b}}$ & $0.0304^{\mathrm{b}}$ & 0.0922 & 0.1041 & $20 q 11.2-q 12$ & MI (35) \\
\hline FLJ14146 & $0.0017^{\mathrm{b}}$ & $0.0151^{\mathrm{b}}$ & 0.2125 & 0.3515 & $1 \mathrm{q} 42.11$ & \\
\hline IMPA2c & $0.0009^{b}$ & $0.0144^{\mathrm{b}}$ & $0.0000^{\mathrm{b}}$ & $0.0000^{\mathrm{b}}$ & $18 \mathrm{p} 11.1$ & \\
\hline INSIG2 & $0.0327^{\mathrm{b}}$ & $0.0327^{\mathrm{b}}$ & 0.1789 & 0.7131 & $2 q 14.2$ & \\
\hline $\mathrm{IRS}^{\mathrm{c}}$ & $0.0079^{\mathrm{b}}$ & $0.0269^{\mathrm{b}}$ & $0.0000^{\mathrm{b}}$ & $0.0000^{\mathrm{b}}$ & $13 q 34$ & \\
\hline KIAA1522 & $0.0288^{\mathrm{b}}$ & $0.0407^{b}$ & 0.5219 & 0.0970 & $1 \mathrm{p} 34.3$ & \\
\hline LILRB2 $^{c}$ & $0.0217^{\mathrm{b}}$ & $0.0176^{\mathrm{b}}$ & $0.0001^{\mathrm{b}}$ & $0.0000^{\mathrm{b}}$ & $19 q 13.4$ & \\
\hline LYPLA2P1 & $0.0015^{\mathrm{b}}$ & $0.0371^{\mathrm{b}}$ & 0.1546 & 0.3801 & $6 \mathrm{p} 21.32$ & \\
\hline MMP19 & $0.0170^{\mathrm{b}}$ & $0.0448^{\mathrm{b}}$ & $0.0304^{\mathrm{b}}$ & 0.0806 & $12 q 14$ & \\
\hline MMP2 & $0.0153^{\mathrm{b}}$ & $0.0267^{\mathrm{b}}$ & 0.0671 & 0.0847 & $16 q 13-q 21$ & \\
\hline MXRA7 & $0.0350^{\mathrm{b}}$ & $0.0103^{b}$ & 0.3040 & 0.8368 & $17 q 25-q 25.2$ & \\
\hline NCOA4 & $0.0176^{\mathrm{b}}$ & $0.0310^{\mathrm{b}}$ & $0.0043^{\mathrm{b}}$ & 0.0556 & $10 \mathrm{q} 11.2$ & \\
\hline PTCRA & $0.0169^{\mathrm{b}}$ & $0.0308^{\mathrm{b}}$ & 0.2364 & 0.0899 & $6 \mathrm{p} 21.3$ & CAD (36) \\
\hline SLC11A1 & $0.0301^{\mathrm{b}}$ & $0.0321^{\mathrm{b}}$ & 0.1664 & 0.0709 & $2 q 35$ & CHD (14) \\
\hline SLC12A7 & $0.0316^{\mathrm{b}}$ & $0.0219^{\mathrm{b}}$ & 0.0719 & 0.1199 & $5 \mathrm{p} 15$ & \\
\hline SLC12A8 ${ }^{c}$ & $0.0096^{\mathrm{b}}$ & $0.0443^{\mathrm{b}}$ & $0.0001^{\mathrm{b}}$ & $0.0036^{\mathrm{b}}$ & $3 q 21.2$ & \\
\hline SLC7A11 ${ }^{\mathrm{c}}$ & $0.0305^{\mathrm{b}}$ & $0.0430^{\mathrm{b}}$ & $0.0002^{\mathrm{b}}$ & $0.0000^{\mathrm{b}}$ & $4 q 28-q 32$ & \\
\hline STUB1 & $0.0215^{\mathrm{b}}$ & $0.0391^{\mathrm{b}}$ & 0.4998 & 0.8438 & $16 \mathrm{p} 13.3$ & CHD (37) \\
\hline ZNF232 & $0.0128^{\mathrm{b}}$ & $0.0079^{\mathrm{b}}$ & $0.0482^{\mathrm{b}}$ & 0.1359 & 17p13-p12 & \\
\hline
\end{tabular}

${ }^{\mathrm{a}}$ Genes are listed by official gene symbol (OMIM). EPB41L1 is listed twice since two probe sets met the criterion. P-values for the comparisons between groups are listed for each gene; ${ }^{b} \mathrm{P}$-values $<0.05$. ${ }^{\mathrm{c}} \mathrm{Gene}$ expression of 7 of the 27 regulated genes was also significantly affected in foam cell formation in both the atherosclerotic and the control group. The chromosomal location of each gene is listed, and previously linkage studies to these chromosomal regions are also included when applicable. Ath, subjects with atherosclerosis; FCHL, familial combined hyperlipidiemia; Homol, homology to mice susceptibility loci Athsq2; MI, myocardial infarction; CAD, coronary artery disease; CHD, coronary heart disease.

proteins, where the $\mathrm{G}$ allele was associated with decreased affinity (17). However, when this SNP was genotyped in the Macrophage INTERGENE study, no differences in gene expression were observed (data not shown).

Genotype association with coronary heart disease. The promoter region polymorphisms of IRS2 and SLC11A1 were also tested for association with CHD in the INTERGENE case-control study.

Subjects with the CC genotype of the $-765 \mathrm{C} \rightarrow \mathrm{T}$ in the promoter region of IRS2 had an increased risk of developing CHD ( $n=512$ successfully genotyped case-control pairs) (Table II).

No association between the genotype for the repeat element of the promoter region of SLC11A1 and CHD was found ( $n=436$ successfully genotyped case-control pairs) (Table II).

In both genotyping experiments, the allele frequencies were in Hardy-Weinberg equilibrium.

IRS2 gene expression. Real-time RT-PCR analysis was used to confirm the elevated gene expression of IRS2 in macrophages and foam cells from subjects with atherosclerosis and the observed upregulation in foam cell formation identified in the DNA microarray analysis (Fig. 3A).

To investigate the mechanism behind regulation of IRS2 in foam cell formation, macrophages were exposed to either rosiglitazone, a known agonist of PPAR $\gamma$, or cyclodextrin, which lowers cellular cholesterol thereby activating SREBP, for $24 \mathrm{~h}$. Rosiglitazone exposure led to increased expression 

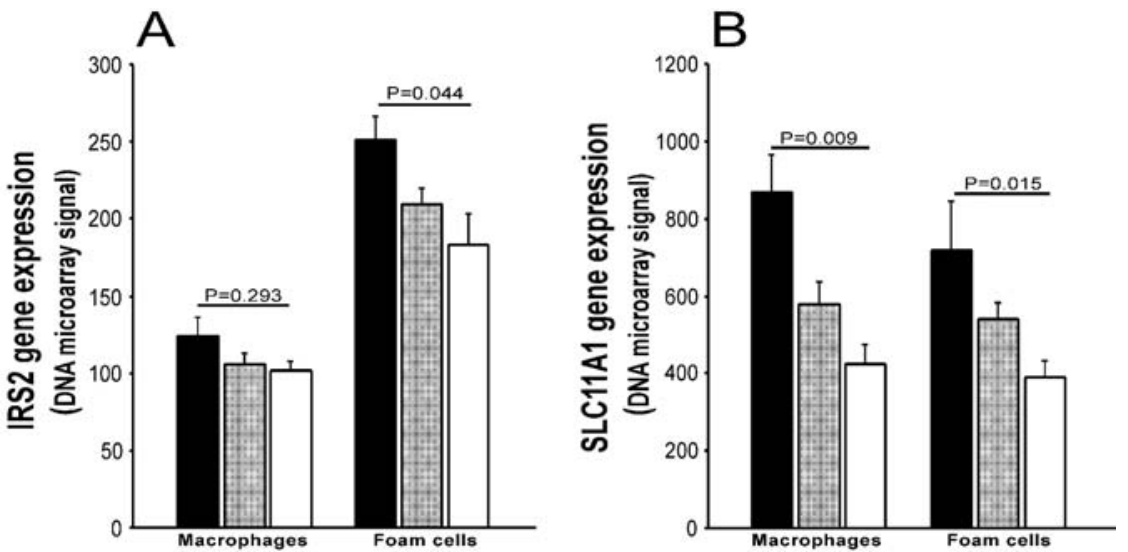

Figure 2. (A) Subjects of the Macrophage INTERGENE study were genotyped for the $-765 \mathrm{C} \rightarrow \mathrm{T}$ SNP in the IRS2 promoter sequence. Foam cells from subjects with the CC genotype (black bars, $\mathrm{n}=13$ ) had a 1.2-fold higher expression than foam cells from subjects with the CT genotype (grey bars, $\mathrm{n}=12$ ) and a 1.4-fold higher expression than foam cells from subjects with the TT genotype (white bars, $\mathrm{n}=2)(\mathrm{P}=0.044)$. Real-time RT-PCR analysis showed the same trend (data not shown). (B) Subjects of the Macrophage INTERGENE study were genotyped for the repeat element of the promoter region of SLC11A1. Macrophages from subjects with the 22 genotype (black bars, $n=3$ ) at the repeat element of the promoter region of SLC11A1 had a 1.5-fold higher gene expression than macrophages from subjects with the 23 genotype (grey bars, $\mathrm{n}=10$ ) and a 2.1 -fold higher gene expression than macrophages from subjects with the 33 genotype (white bars, $\mathrm{n}=14)(\mathrm{P}=0.009)$. In foam cells, the fold change was 1.3 between subjects with the 22 genotype and 23 genotype and 1.8 between subjects with the 22 genotype and 33 genotype $(\mathrm{P}=0.015)$.

Table II. Genotyping of promoter region polymorphisms of IRS2 and SLC11A1 in the INTERGENE study. ${ }^{\mathrm{a}}$

\begin{tabular}{|c|c|c|c|c|c|}
\hline Gene & Polymorphism & Odds ratio & $95 \% \mathrm{CI}$ & P-value & $\mathrm{n}$ \\
\hline IRS2 & $-765 \mathrm{C} \rightarrow \mathrm{T}$ & 1.43 & $1.10-1.86$ & 0.010 & 512 \\
\hline SLC11A1 & GT-repeat & 1.15 & $0.68-1.51$ & 0.689 & 436 \\
\hline
\end{tabular}

${ }^{\mathrm{a}}$ Mantel-Haenzels odds ratio for paired data and the McNemar's test were used. Subjects were divided into CC and nonCC genotypes for the IRS2 SNP, and 22 and non22 genotypes for the SLC11A1 repeat element. N, number of case-control pairs successfully genotyped.
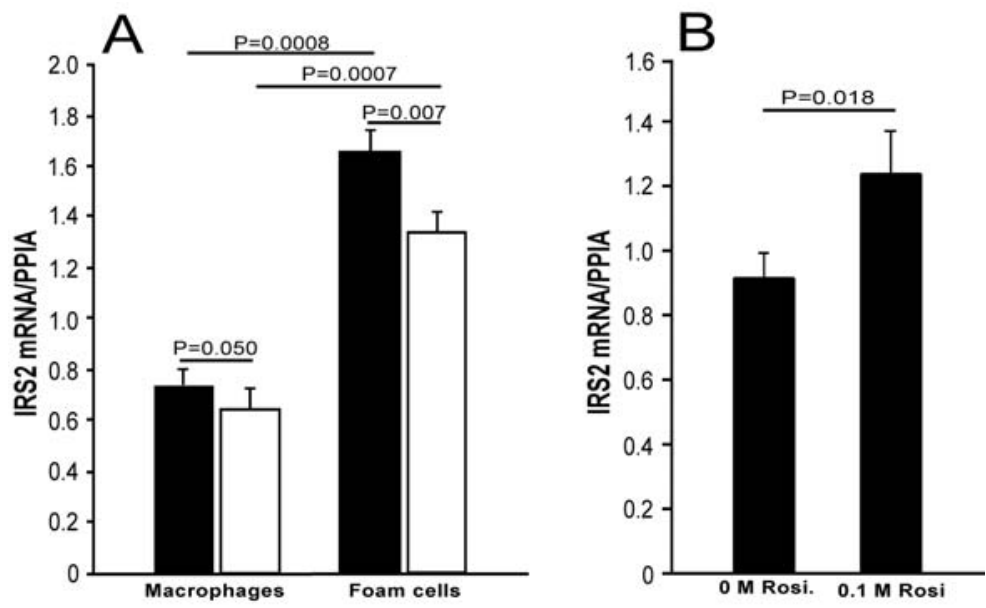

Figure 3. (A) Real-time RT-PCR verification of IRS2 gene expression in macrophages and foam cells from the subjects with atherosclerosis (black bars, $\mathrm{n}=15$ ) and from the controls (white bars, $\mathrm{n}=15$ ). (B) Macrophages $(\mathrm{n}=8)$ that were exposed to $0.1 \mu \mathrm{M}$ rosiglitazone for $24 \mathrm{~h}$ had 1.4 -fold increased IRS2 gene expression compared to control macrophages.

of IRS2 (Fig. 3B) whereas cyclodextrin had no effect on IRS2 expression (data not shown).

Expression in human carotid plaques. To investigate the in vivo protein expression of IRS2 in atherosclerotic plaques, immunohistochemical staining of human carotid endarterectomies $(n=4)$ with an anti-IRS2 antibody was performed (Fig. 4). IRS2 protein expression (A) co-localized with macrophage-rich sections identified by an antibody against CD68 (B). In addition, IRS2 was also expressed in 

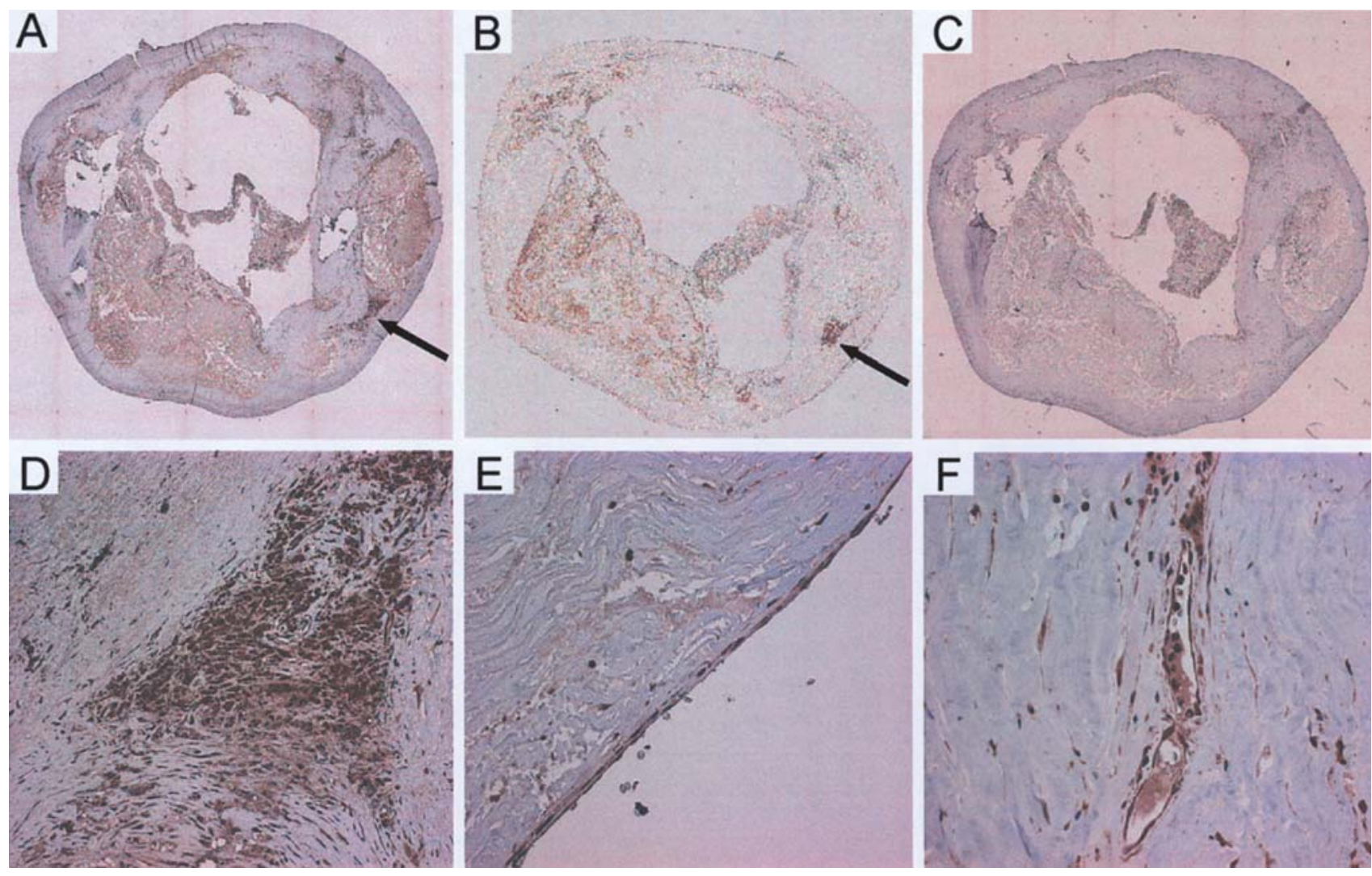

Figure 4. IRS2 expression in human carotid endarterectomy atherosclerotic plaques. Full section image of staining with antibodies against IRS2 (A) and CD68 (B). The arrows point to the same macrophage-rich area in subsequent sections. A negative control section with omitted primary antibody (C). High magnification image of IRS2 staining in a macrophage-rich area of the plaque (D), endothelial cells lining the vascular lumen (E) and endothelial cells in plaque microvessels $(\mathrm{F})$.

endothelial cells facing lumen and endothelial cells in neovascularization ( $\mathrm{E}$ and $\mathrm{F}$ ).

\section{Discussion}

The aim of this study was to identify novel susceptibility genes for atherosclerosis and CHD using expression profiles of human macrophages. Twenty-seven genes were identified as differentially expressed between macrophages from subjects with atherosclerosis and macrophages from control subjects. Three genes were selected for further study: IRS2, CD86 and SLC11A1.

First, we tried to establish a link between the altered gene expression in macrophages from subjects with atherosclerosis and macrophages from control subjects and genetic variability. We found that subjects with the CC genotype of the $-765 \mathrm{C} \rightarrow \mathrm{T}$ polymorphism in the IRS 2 promoter region had higher gene expression than subjects with the CT or TT genotype in foam cells, with a similar tendency in macrophages. Subjects with the CC genotype had 1.2-fold higher expression than nonCC in foam cells. This is in line with a previous study by Iwamoto et al, who found that the $-765 \mathrm{C} \rightarrow \mathrm{T}$ substitution decreased IRS2 promoter activity in cell lines using a luciferase assay, where the T allele exhibited $80 \%$ expression compared to the $\mathrm{C}$ allele (13).

The repeat element in the SLC11A1 promoter region was first described by Searle and Blackwell (14), who identified four different alleles, that have an impact on gene expression
(18). Since SLC11A1 gene expression was higher in macrophages from subjects with atherosclerosis than in macrophages from control subjects, we genotyped these subjects for the promoter repeat element. Subjects homozygous for allele 2 had significantly higher gene expression than non22subjects, however only 3 of 27 successfully genotyped subjects were homozygous for allele 2 . This is contrary to the results reported by Searle and Blackwell (14), who reported higher expression of allele 3 using a luciferase assay.

The effect of CD86 on atherogenesis is unclear and poorly investigated. CD80 and CD86 double-deficient mice generated on a $\mathrm{LDLR}^{-/}$background developed decreased atherosclerosis (10), but $\mathrm{LDLR}^{-/}$mice receiving bone marrow from $\mathrm{CD} 80^{-/} \mathrm{CD}^{-/-}$mice grew larger atherosclerotic plaques (15). Genotyping of the rs 2715267 SNP in the promoter region of CD86 showed no association with gene expression.

We thereafter genotyped the subjects of the INTERGENE population study. Subjects homozygous for the $\mathrm{C}$ allele of the $-765 \mathrm{C} \rightarrow \mathrm{T}$ SNP in the promoter region of IRS 2 had a $40 \%$ increased risk of CHD. This is a rather modest risk increase, which is in line with the assumption that several genes with rather small individual impact contribute to the total risk for atherosclerosis and CHD. For example, three recent studies associated the 9p21.3 loci with CAD (16-18), with odds ratio estimations varying between 1.3-1.6.

The association between IRS2 and CHD led us to explore this finding further. We assessed the mechanism behind the induction of IRS2 gene expression during foam cell 
formation. Our finding that rosiglitazone induces IRS2 expression in macrophages suggests that induction of IRS2 in foam cell formation at least in part may be mediated through PPAR $\gamma$, which is known to be induced by oxidized LDL (19). Previous studies have shown that PPAR $\gamma$ increases IRS2 gene expression in adipocytes (20). In contrast, the addition of cyclodextrin to macrophage cell culture media did not affect IRS2 gene expression. Cholesterol depletion activates SREBP (21), a known suppressor of IRS2 in the liver (22). However, since we did not observed any decrease in IRS2 gene expression in cyclodextrin-treated macrophages, this suggests that IRS2 is differentially regulated in macrophages compared to the liver.

To investigate IRS2 protein expression in vivo we used immunohistochemistry to verify that IRS2 protein is expressed in macrophages in human carotid plaques, and we also found that IRS2 is expressed in endothelial cells facing lumen and in neovascularization.

IRS2 belongs to the insulin receptor substrate family, a group of proteins that mediate intracellular signalling in response to insulin, insulin-like growth factor 1 and various cytokines (23). The implication of IRS2 in the context of atherosclerosis has been studied only to a limited extent in animal models, and the underlining mechanisms are poorly understood. It has been established that IRS2 $2^{-/}$mice develop diabetes $(28,29)$. The insulin-resistant IRS2 $2^{-/}$mice have enhanced neointima formation in response to injury and have significantly higher triglyceride and cholesterol levels, as well as higher systolic blood pressure than wild-type mice (24). IRS2 $2^{+/} \mathrm{ApoE}^{-/-}$mice have increased atherosclerosis compared to $\mathrm{ApoE}^{-/-}$mice (25). On the other hand, $\mathrm{ApoE}^{-/-}$ mice lethally irradiated and reconstituted with $\mathrm{ApoE}^{-/} \mathrm{IRS} 2^{-/-}$ haematopoietic cells have smaller lesions than mice reconstituted with $\mathrm{ApoE}^{-/} \mathrm{IRS} 2^{+/+}$cells (11). These findings indicate a difference in systemic and peripheral function of IRS2 in the development of atherosclerosis. This is also in line with studies showing that IRS2 has different functions in different cell types and tissues. For example, Sadagurski et al showed that IRS2 can act both as an activator and a suppressor of glucose transport in a cell-specific manner (26). IRS2 polymorphisms have previously been linked to both obesity (27) and diabetes (28), which in combination with our findings indicates that normal function of this gene is required for a balanced and healthy metabolism.

In conclusion, our screening procedure to identify novel susceptibility genes for atherosclerosis and CHD proved to be successful. IRS2 gene expression was higher in macrophages and foam cells from subjects with atherosclerosis compared to macrophages and foam cells from control subjects, and IRS2 expression co-localised with macrophages in atherosclerotic plaques in vivo. Subjects with the CC genotype of the $-765 \mathrm{C} \rightarrow \mathrm{T}$ SNP in the promoter region of IRS2 were associated with higher macrophage IRS2 gene expression and an increased risk of CHD. We conclude that IRS2 may be a new susceptibility gene for atherosclerosis.

\section{Acknowledgements}

The authors thank Karin Ekström, Josefin Kjelldal and Helena Samuelsson for their excellent technical assistance.
This work was supported by The Swedish Foundation for Strategic Research to Sahlgrenska Center for Cardiovascular and Metabolic Research, The Swedish Research Council (11285), The Swedish Heart Lung Foundation, AFA, The Sahlgrenska University Hospital Foundation, The Foundations of the National Board of Health and Welfare, Wilhelm och Martina Lundgren Foundation, The Swedish Diabetes Foundation, Goljes Minne Foundation, Swegene, Fredrik and Ingrid Thuring Foundation and the Swedish federal government under the LUA/ALF agreement.

\section{References}

1. Lusis AJ, Mar R and Pajukanta P: Genetics of atherosclerosis. Annu Rev Genomics Hum Genet 5: 189-218, 2004.

2. Risk of fatal coronary heart disease in familial hypercholesterolaemia. Scientific Steering Committee on behalf of the Simon Broome Register Group. BMJ 303: 893-896, 1991.

3. Seo D, Ginsburg GS and Goldschmidt-Clermont PJ: Gene expression analysis of cardiovascular diseases: novel insights into biology and clinical applications. J Am Coll Cardiol 48: 227-235, 2006.

4. Cowles CR, Hirschhorn JN, Altshuler D and Lander ES: Detection of regulatory variation in mouse genes. Nat Genet 32: 432-437, 2002.

5. Berg C, Rosengren A, Aires N, et al: Trends in overweight and obesity from 1985 to 2002 in Göteborg, West Sweden. Int J Obes 29: 916-924, 2005.

6. Hägg D, Sjoberg S, Hulten LM, et al: Augmented levels of CD44 in macrophages from atherosclerotic subjects: A possible IL-6-CD44 feedback loop? Atherosclerosis 190: 291-297, 2006.

7. Svensson PA, Englund MC, Snackestrand MS, et al: Regulation and splicing of scavenger receptor class B type I in human macrophages and atherosclerotic plaques. BMC Cardiovasc Disord 5: 25, 2005.

8. Steinberg D: Low density lipoprotein oxidation and its pathobiological significance. J Biol Chem 272: 20963-20966, 1997.

9. Hägg D, Englund MC, Jernas M, et al: Oxidized LDL induces a coordinated up-regulation of the glutathione and thioredoxin systems in human macrophages. Atherosclerosis 185: 282-289, 2006.

10. Buono C, Pang H, Uchida Y, Libby P, Sharpe AH and Lichtman AH: B7-1/B7-2 costimulation regulates plaque antigen-specific T-cell responses and atherogenesis in lowdensity lipoprotein receptor-deficient mice. Circulation 109: 2009-2015, 2004.

11. Baumgartl J, Baudler S, Scherner M, et al: Myeloid lineage cellrestricted insulin resistance protects apolipoproteinE-deficient mice against atherosclerosis. Cell Metab 3: 247-256, 2006.

12. Chiodini BD and Lewis CM: Meta-analysis of 4 coronary heart disease genome-wide linkage studies confirms a susceptibility locus on chromosome 3q. Arterioscler Thromb Vasc Biol 23: 1863-1868, 2003.

13. Iwamoto K, Mori H, Okazawa H, Hashiramoto M and Kasuga M: Identification of a single nucleotide polymorphism showing no insulin-mediated suppression of the promoter activity in the human insulin receptor substrate 2 gene. Diabetologia 45: 1182-1195, 2002.

14. Searle S and Blackwell JM: Evidence for a functional repeat polymorphism in the promoter of the human NRAMP1 gene that correlates with autoimmune versus infectious disease susceptibility. J Med Genet 36: 295-299, 1999.

15. Ait-Oufella H, Salomon BL, Potteaux S, et al: Natural regulatory $\mathrm{T}$ cells control the development of atherosclerosis in mice. Nat Med 12: 178-180, 2006.

16. Samani NJ, Erdmann J, Hall AS, et al: Genomewide association analysis of coronary artery disease. N Engl J Med 357: 443-453, 2007.

17. Helgadottir A, Thorleifsson G, Manolescu A, et al: A common variant on chromosome 9p21 affects the risk of myocardial infarction. Science 316: 1491-1493, 2007.

18. McPherson R, Pertsemlidis A, Kavaslar N, et al: A common allele on chromosome 9 associated with coronary heart disease. Science 316: 1488-1491, 2007. 
19. Nagy L, Tontonoz P, Alvarez JG, Chen H and Evans RM: Oxidized LDL regulates macrophage gene expression through ligand activation of PPARgamma. Cell 93: 229-240, 1998.

20. Smith U, Gogg S, Johansson A, Olausson T, Rotter V and Svalstedt B: Thiazolidinediones (PPARgamma agonists) but not PPARalpha agonists increase IRS-2 gene expression in 3T3-L1 and human adipocytes. FASEB J 15: 215-220, 2001.

21. Yeh M, Cole AL, Choi J, et al: Role for sterol regulatory elementbinding protein in activation of endothelial cells by phospholipid oxidation products. Circ Res 95: 780-788, 2004.

22. Ide T, Shimano H, Yahagi N, et al: SREBPs suppress IRS-2mediated insulin signalling in the liver. Nat Cell Biol 6: 351-357, 2004.

23. White MF: The IRS-signaling system: a network of docking proteins that mediate insulin and cytokine action. Recent Prog Horm Res 53: 119-138, 1998

24. Kubota T, Kubota N, Moroi M, et al: Lack of insulin receptor substrate-2 causes progressive neointima formation in response to vessel injury. Circulation 107: 3073-3080, 2003.
25. Clough MH, Schneider DJ, Sobel BE, White MF, Wadsworth MP and Taatjes DJ: Attenuation of accumulation of neointimal lipid by pioglitazone in mice genetically deficient in insulin receptor substrate-2 and apolipoprotein e. J Histochem Cytochem 53: 603-610, 2005.

26. Sadagurski M, Weingarten G, Rhodes CJ, White MF and Wertheimer E: Insulin receptor substrate 2 plays diverse cellspecific roles in the regulation of glucose transport. J Biol Chem 280: 14536-14544, 2005

27. Lautier C, El Mkadem SA, Renard E, et al: Complex haplotypes of IRS2 gene are associated with severe obesity and reveal heterogeneity in the effect of Gly1057Asp mutation. Hum Genet 113: 34-43, 2003.

28. Mammarella S, Romano F, Di Valerio A, et al: Interaction between the G1057D variant of IRS-2 and overweight in the pathogenesis of type 2 diabetes. Hum Mol Genet 9: 2517-2521, 2000 . 